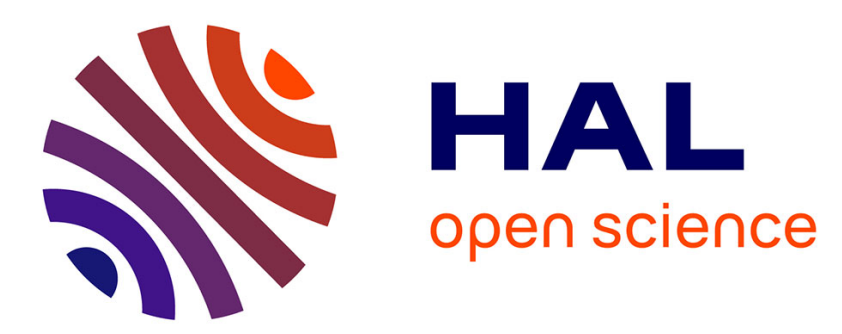

\title{
Physico-chemical properties of nanocrystalline apatites: Implications for biominerals and biomaterials
}

\author{
Christian Rey, Christèle Combes, Christophe Drouet, Hocine Sfihi, Allal
} Barroug

\section{- To cite this version:}

Christian Rey, Christèle Combes, Christophe Drouet, Hocine Sfihi, Allal Barroug. Physico-chemical properties of nanocrystalline apatites: Implications for biominerals and biomaterials. Materials Science and Engineering: C, 2007, vol. 27, pp. 198-205. 10.1016/j.msec.2006.05.015 . hal-00808375

\section{HAL Id: hal-00808375 \\ https://hal.science/hal-00808375}

Submitted on 5 Apr 2013

HAL is a multi-disciplinary open access archive for the deposit and dissemination of scientific research documents, whether they are published or not. The documents may come from teaching and research institutions in France or abroad, or from public or private research centers.
L'archive ouverte pluridisciplinaire HAL, est destinée au dépôt et à la diffusion de documents scientifiques de niveau recherche, publiés ou non, émanant des établissements d'enseignement et de recherche français ou étrangers, des laboratoires publics ou privés. 


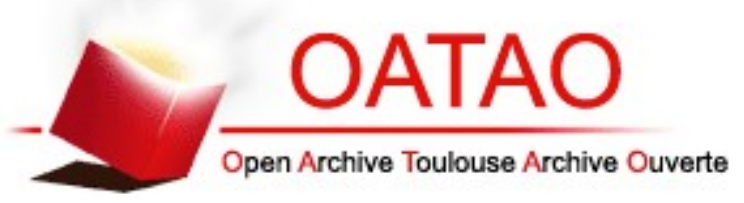

\section{Open Archive Toulouse Archive Ouverte (OATAO)}

OATAO is an open access repository that collects the work of Toulouse researchers and makes it freely available over the web where possible.

This is an author-deposited version published in: http://oatao.univ-toulouse.fr/ Eprints ID : 2484

To link to this article :

URL : http://dx.doi.org/10.1016/j.msec.2006.05.015

To cite this version : Rey, Christian and Combes, Christèle and Drouet, Christophe and Sfihi, H. and Barroug, A. (2007) Physico-chemical properties of nanocrystalline apatites: Implications for biominerals and biomaterials. Materials Science and Engineering C, vol. 27 ( $\mathrm{n}^{\circ}$ 2). pp. 198-205. ISSN 0928-4931

Any correspondence concerning this service should be sent to the repository administrator:staff-oatao@inp-toulouse.fr 


\title{
Physico-chemical properties of nanocrystalline apatites: Implications for biominerals and biomaterials
}

\author{
C. Rey ${ }^{\mathrm{a}, *}$, C. Combes ${ }^{\mathrm{a}}$, C. Drouet ${ }^{\mathrm{a}}$, H. Sfihi $^{\mathrm{b}}$, A. Barroug ${ }^{\mathrm{c}}$ \\ ${ }^{a}$ CIRIMAT, ENSIACET-INPT, UMR CNRS 5085, 118 route de Narbonne, 31077 Toulouse Cedex 04, France \\ ${ }^{\mathrm{b}}$ Laboratoire de Physique Quantique, UMR CNRS 7142 ESPCI, 10 rue Vauquelin, Paris, France \\ c Département de Chimie, Faculté des Sciences Semlalia, Boulevard Prince My Abdellah, BP 2390 Marrakech 40001, Morocco
}

\begin{abstract}
Nanocrystalline apatites play an important role in biomineralisation and they are used as bioactive biominerals for orthopaedic applications. One of the most interesting characteristics of the nanocrystals, evidenced by spectroscopic methods, is the existence of a structured surface hydrated layer, well developed in freshly formed precipitates, which becomes progressively transformed into the more stable apatitic lattice upon ageing in aqueous media. The hydrated layer is very fragile and irreversibly altered upon drying. Several routes leading to different apatite compositions are found in biological systems. The loosely bound ions of the hydrated layer can be easily and reversibly substituted by other ions in fast aqueous ion exchange reactions. These ions can either be included in the growing stable apatite lattice during the ageing process or remain in the hydrated layer. The adsorption properties of nanocrystals appear to be strongly dependent on the composition of the hydrated layer and on ageing. The surface reactivity of the apatite nanocrystals can play a part in different biomaterials and could explain the setting reactions of biomimetic calcium phosphate cements and the possibility of obtaining adherent nanocrystalline coatings on different substrates.
\end{abstract}

Keywords: Apatite; Nanocrystals; Bone; Ceramics; Coatings

\section{Introduction}

Although apatites are among the most stable and most easily formed calcium phosphates, their composition, and crystal structure are still the object of intense research [1-5]. Apatite nanocrystals especially occur in bone tissues and other biological mineralisations; however, their composition structure and properties are generally not accurately known, and bone mineral is often thought of and presented as a single chemical compound despite broad variations depending on type, age, species and even strains. The effects of various diseases on bone mineral have not yet been determined in depth. This lack of interest is mainly due to difficulties of characterisation and to the belief that bone mineral is inert and that, except for its passive role in the mechanical properties of calcified tissue and as an ion reservoir, it is not acting as a dynamic constituent in biological regulation processes. However, due to the very high specific area

\footnotetext{
* Corresponding author. Tel.: +33 5628856 35; fax: +33 562885773 . E-mail address: Christian.Rey@ensiacet.fr (C. Rey).
}

of the crystals, the mineral could participate in several basic equilibria, involving for example specific proteins or mineral ions adsorption and release. A similar situation exists in the biomaterials field where apatite nanocrystals are considered to play a major role in the biological activity of materials [6-8] but they remain rather poorly defined and characterised. The formation of a nanocrystalline apatite layer at the surface of implant materials has been recognised as playing a determinant role in their bone-bonding ability [6]. However, the terms "bonelike crystals", "biomimetic crystals" have little meaning and they do not generally refer to a composition or even to a structure but simply to a crystallographic pattern or a microscopic appearance analogous to that of bone mineral. The poor knowledge and characterisation of apatite nanocrystals may result in inconsistencies and disagreement in experimental results. For example, the conditions of nanocrystal formation are thought to affect their biological performance [9]. The relationship between the characteristics of the crystals and their biological activity is still unknown, however. Despite difficulties in accurately characterising the composition, the structural details 
and the properties of apatite nanocrystals, progress in this domain is essential to develop the use of apatite nanocrystals in biomaterials and to reach a better understanding of the role and behaviour of bone mineral. Several interesting techniques can be used to characterise apatite nanocrystals more precisely [10-13].

\section{Apatite composition}

Calcium phosphate hydroxyapatite,

$\mathrm{Ca}_{10}\left(\mathrm{PO}_{4}\right)_{6}(\mathrm{OH})_{2}$

is generally considered as a model compound for biological mineralisations although this ideal formula is never actually found. The composition of well crystallised apatites has been shown to vary over a wide range due to the possibilities of anionic and cationic substitutions and the existence of different types of ion vacancies. Several models have been proposed [14] and one of the most relevant concerning bone mineral was established by Bonel [15]. It was shown that the substitution of a $\mathrm{PO}_{4}^{3-}$ group by bivalent species such as $\mathrm{HPO}_{4}^{2-}$ or $\mathrm{CO}_{3}^{2-}$ is compensated for by the formation of cationic vacancies and anionic vacancies in the $\mathrm{OH}^{-}$site:

$\mathrm{Ca}_{10-x}\left(\mathrm{PO}_{4}\right)_{6-x}\left(\mathrm{HPO}_{4}^{2-} \text { or } \mathrm{CO}_{3}^{2-}\right)_{x}(\mathrm{OH})_{2-x}$ with $0 \leq x \leq 2$

This model was then improved to take into account variations in the composition of synthetic apatites, which generally show an excess of calcium and $\mathrm{OH}^{-}$ions due to the preparation conditions in alkaline media,

$\mathrm{Ca}_{10-x+u}\left(\mathrm{PO}_{4}\right)_{6-x}\left(\mathrm{HPO}_{4}^{2-} \text { or } \mathrm{CO}_{3}^{2-}\right)_{x}(\mathrm{OH})_{2-x+2 u}$

with $0 \leq x \leq 2$ and $0 \leq u \leq x / 2$

In some other cases, however, defects of $\mathrm{Ca}^{2+}$ and $\mathrm{OH}^{-}$have been reported. Then the " $u$ " parameter can be negative in the above formulae giving $-u \leq 1-x / 2$. All phosphate sites seem to be occupied in apatites either by trivalent or bivalent ions.

A complication may appear in the event of internal hydrolysis of $\mathrm{PO}_{4}^{3-}$ ions by water molecules $[15,16]$, which may create additional $\mathrm{HPO}_{4}^{2-}$ and $\mathrm{OH}^{-}$:

$\mathrm{PO}_{4}^{3-}+\mathrm{H}_{2} \mathrm{O} \rightarrow \mathrm{HPO}_{4}^{2-}+\mathrm{OH}^{-}$

In this case, formula (3) can be corrected to:

$$
\begin{aligned}
& \mathrm{Ca}_{10-x+u}\left(\mathrm{PO}_{4}\right)_{6-x-y}\left(\mathrm{HPO}_{4}^{2-} \text { or } \mathrm{CO}_{3}^{2-}\right)_{x+y}(\mathrm{OH})_{2-x+2 u+y} \\
& \text { with } 0 \leq x \leq 2 \text { and } 0 \leq 2 u+y \leq x
\end{aligned}
$$

which can be considered as the most general formula for nonstoichiometric apatites.

It is not generally possible to determine $x, u$ and $y$ in biological apatites, due to the difficulties in determining the $\mathrm{OH}^{-}$ content and the amount of $\mathrm{HPO}_{4}^{2-}$, especially when carbonate ions are present. It is generally considered that the " $u$ " parameter can be ignored in biological apatites formed at nearly neutral $\mathrm{pH}$ and that internal hydrolysis ( $y$ parameter) has no effect. Thus, formula (2) can be considered as an approximation of the composition of biological apatites [17].
Another model of non-stoichiometric apatites has been proposed by Brown, who considers them as an interlayering of apatite and octacalcium phosphate (OCP) domains [18]. The formation of layers could be facilitated by the structure of OCP consisting of the superimposition of an apatite plane, one unitcell thick, and a hydrated layer [19]. The composition of such interlayered compounds could then appear as intermediate between that of OCP:

$$
\mathrm{Ca}_{8}\left(\mathrm{PO}_{4}\right)_{4}\left(\mathrm{HPO}_{4}\right)_{2}, 5 \mathrm{H}_{2} \mathrm{O}
$$

and that of stoichiometric apatite (1), and could be represented by a chemical formula similar to Eq. (2), but containing variable quantities of water. However, the main drawback of this concept is that it cannot describe carbonated apatite which is in fact the principal component of biological apatites.

Other substituents may enter the apatitic lattice such as trivalent (e.g. rare earth elements, actinides) or monovalent cations (especially $\mathrm{Na}^{+}$) replacing $\mathrm{Ca}^{2+}$, tetravalent ions replacing $\mathrm{PO}_{4}^{3-}$, and bivalent ions replacing $\mathrm{OH}^{-}$, and several charge compensation mechanisms have been proposed [14]. However such possibilities seem to have a minor influence on the chemical formula of the apatites in calcified tissues due to the low amounts of these foreign ions.

The case of nanocrystalline apatites, however, seems more complex as several ions may be located at the surface of the crystals. Thus, early works suggested that $\mathrm{Mg}^{2+}$ and $\mathrm{CO}_{3}^{2-}$ could remain on the surface of the apatite crystals [20,21]. Then the global composition of such crystals can differ from the proposed chemical formulae which do not consider surface ions although they can represent an important fraction in nanocrystals. This point will be clarified later.

\section{Structure of apatite nanocrystals}

Biological $\mathrm{Ca}-\mathrm{P}$ minerals were once considered as a mixture of phases due to their variable and complex composition. It is now established that they are formed by a single apatitic phase, and the presence of foreign phases in normal mineralised tissues has never been reproducibly established. Due to their nanocrystalline nature and the heterogeneity of biological mineralisations, diffraction techniques have not yet given much information on the fine structural details related to the crystals. Most recent progress has relied on spectroscopic methods, which are sensitive to the disturbance of the environments of the mineral ions [10-13]. One of the most striking features of nanocrystalline apatites of biological or synthetic origin is the presence of "non-apatitic" environments of the mineral ions $[12,13]$. These environments have been constantly and reproducibly observed using different spectroscopic methods such as FTIR [12,13], solid-state NMR [22-24] and XANES [25]. FTIR spectra of nanocrystalline apatites, in the $v_{4} \mathrm{PO}_{4}$ domain, reveal the existence of additional bands of phosphate ions which cannot be assigned to an apatitic environment and which are not present in well crystallised apatites (Fig. 1). These bands have been assigned to non-apatitic environments of phosphate and hydrogenphosphate ions of the nanocrystals, and 


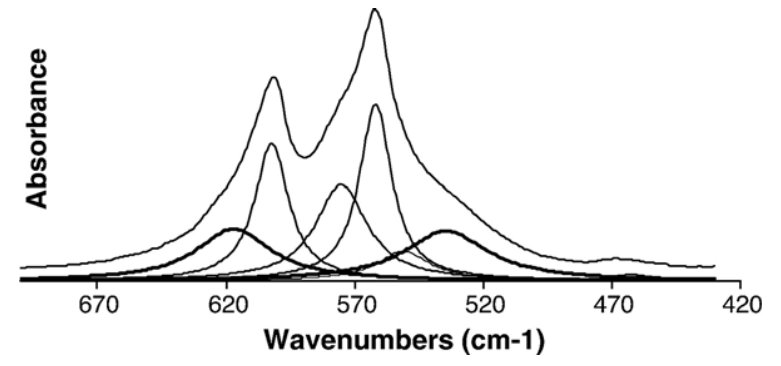

Fig. 1. FTIR spectra of poorly crystalline apatites showing the non-apatitic environments of the phosphate ions (bold lines, 617 and $634 \mathrm{~cm}^{-1}$ ) and the apatitic $\mathrm{PO}_{4}^{3-}\left(600,575\right.$ and $\left.560 \mathrm{~cm}^{-1}\right)$ and $\mathrm{HPO}_{4}^{2-}\left(550 \mathrm{~cm}^{-1}\right)$ in the $v_{4} \mathrm{PO}_{4}$ domain.

FTIR spectra can be used to provide a sufficiently accurate evaluation of the amounts of such environments. Similar observations have been made in the $v_{2} \mathrm{CO}_{3}$ domain and they have been confirmed by solid-state NMR measurements $[22,24]$. In addition, this technique revealed that the nonapatitic environments correspond to hydrated domains (Fig. 2) of the nanocrystals distinct from apatite domains. More recently, it has been shown by XANES at the Ca K-edge that specific environments of $\mathrm{Ca}^{2+}$ ions were also found for nanocrystals, which did not occur in well crystallised apatites [12,13]. The existence of "non-apatitic environments" of calcium ions completes the picture of these specific domains. It has been suggested that such hydrated domains could be located at the surface of the nanocrystals, lowering their interfacial energy in aqueous media [26].

The spectroscopic methods first used to characterise apatite nanocrystals were applied to dry nanocrystals as usual for most

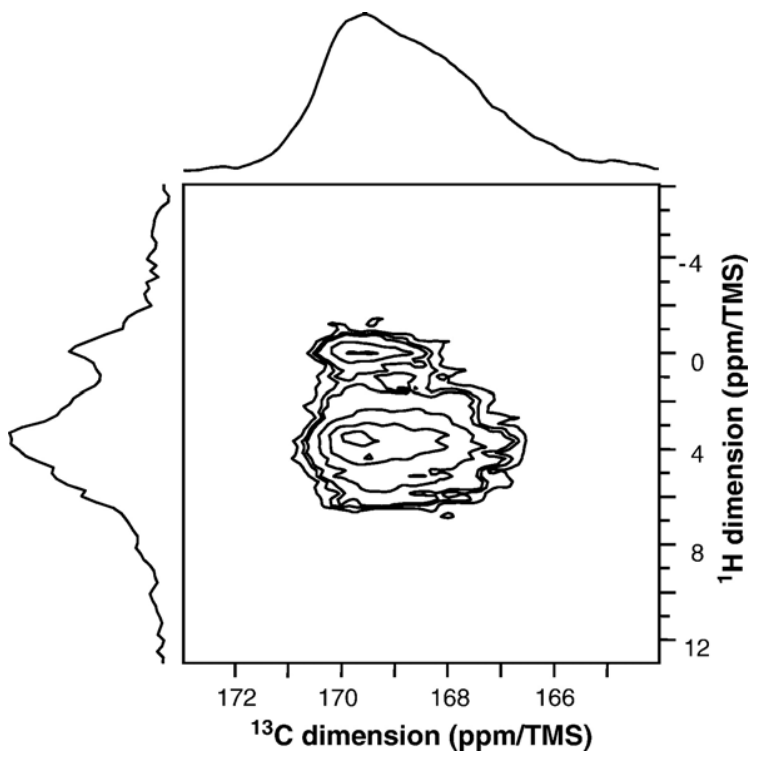

Fig. 2. Contours and projections of 2-D ${ }^{1} \mathrm{H} \leftrightarrow{ }^{13} \mathrm{C}$ HetCor - MAS NMR of type B carbonate fluorhydroxyapatite [24]. They clearly show the existence of two carbonate species: type $\mathrm{B}$ carbonate (carbonate substituted for $\mathrm{PO}_{4}^{3-}$ ions in the apatite domains) at $169.5 \mathrm{ppm}$ correlated mainly with $\mathrm{OH}^{-}$ions located in the apatitic channels $(0.2 \mathrm{ppm})$, and non-apatitic carbonate species $(168.5 \mathrm{ppm})$ correlated with water molecules $(6 \mathrm{ppm})$ and belonging to hydrated domains. minerals. One may, however, wonder if drying such fragile structures does not disturb them. Therefore, spectroscopic methods have been used to characterise the nanocrystals in the wet state i.e. as they occur in nature. The data obtained either by FTIR or by solid state NMR show that freshly precipitated nanocrystals exhibit specific sharp lines which are lost on drying [26,27] (Fig. 3). These lines have been assigned to a transient stage in nanocrystal precipitation, corresponding to the existence of a structured hydrated layer. Careful analysis of the spectra suggests that the hydrated layer is different from that existing in well crystallised hydrated $\mathrm{Ca}-\mathrm{P}$ compounds such as DCPD (dicalcium phosphate dihydrate) and OCP, although a striking analogy is found between the FTIR spectra of wet nanocrystals and that of OCP [26]. These specific features do not correspond to any alteration of the diffraction patterns, indicating that the hydrated domains do not develop in 3-dimensional periodic structures and cannot be considered as a new phase. The structured hydrated domains disappear upon drying, giving way to still partly hydrated domains corresponding to the "non-apatitic environments". However, even in wet media such structured hydrated domains seem very unstable and progressively fade away as the precipitate ages in solution. This "maturation" phenomenon of the precipitates clearly shows the instability of the hydrated structured layer compared to the slow-forming apatitic domains. These data suggest that apatite crystals form in a complex manner involving a labile hydrated layer which progressively becomes transformed into stable apatite domains. These formation conditions could explain the abnormal plate-like shape of the crystals exhibiting asymmetric growth along the two equivalent directions perpendicular to the $c$ axis of the hexagonal unit cell of apatite [14]. The surface structure of apatite nanocrystals could also occur in larger apatite crystals formed in aqueous media; however, due to an unfavourable surface/volume ratio they cannot be detected by spectroscopic methods although some indications may be obtained, especially by XPS [28].

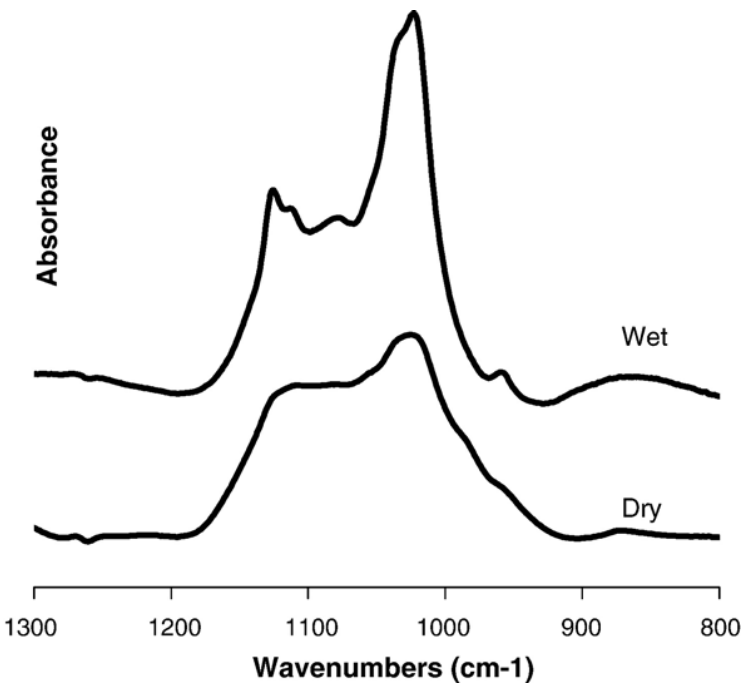

Fig. 3. Effect on drying on the ionic environment as shown by FTIR spectroscopy in the $v_{3} \mathrm{PO}_{4}^{3-}$ domain [26]. In the wet state narrow well defined bands are seen indicative structured environments of the mineral ions. These environments are lost on drying and broader bands are observed. 
The hydrated surface layer confers unexpected properties to apatite nanocrystals, properties which living organisms benefit from and which could be used in material science as well to obtain bioactive coatings or bulk ceramics from nanocrystals.

\section{Physical-chemical properties of apatite nanocrystals}

Several properties depend on the existence of the unstable hydrated layer containing relatively mobile mineral ions.

\subsection{Maturation and organ properties}

The ageing of apatite nanocrystals can lead to very different characteristics of the resulting mineral, the properties of which can be adapted to the functions of the organs. One of the most interesting examples is given by tooth enamel. At early stages, the composition of enamel crystals is very close to that of embryonic bone crystals, very rich in non-apatitic environments [29]. However, as the tissue develops, the proportion of nonapatitic environments decreases as do the levels of carbonate and hydrogen phosphate, whereas the amount of $\mathrm{OH}^{-}$ions increases, indicating a decrease of the proportion of vacancies and leading to the formation of large crystals closer to stoichiometric apatite with a low solubility. In the case of bone mineral, maturation also leads to a decrease of the nonapatitic environments. Concomitantly, the $\mathrm{HPO}_{4}^{2-}$ content decreases, whereas the amount of carbonate increases and no (or a very few) $\mathrm{OH}^{-}$ions are detected [30]. Overall, the proportion of vacancies does not decrease in bone apatites during ageing. The study of the maturation of synthetic apatites in aqueous media allows the bone and enamel mineral maturation to be mimicked. In the presence of carbonate ions in solution apatite nanocrystals evolve as they do in bone. Carbonate ions incorporated in the hydrated layer slow down the development of the apatitic domain (carbonate ions are known as apatite crystal growth inhibitors). Moreover, as the carbonate ions are incorporated into the slowly growing apatite domain, they maintain a high vacancy content, unlike in enamel crystal evolution. Thus, bone crystals can be easily dissolved to maintain homeostasis and during remodelling. In the absence of carbonate, the decrease of non-apatitic domains occurs more rapidly and is accompanied, as in enamel crystals, by crystal growth and the formation of apatite crystals closer to the stoichiometry of hydroxyapatite. The composition of apatite crystals then appears more related to the maturation conditions than to the precipitation conditions. The use of ${ }^{13} \mathrm{C}$ labelling of carbonate ions gives more information on the process of maturation of apatite nanocrystals (Fig. 4). The carbonate ions are introduced progressively in the apatite lattice during the growth of apatite domains and once they have been incorporated they cannot be replaced by ions from the solution (there is no dissolution-reprecipitation of the crystals, but surface re-equilibration). The amount of carbonate ions incorporated is related to the amount of non-apatitic environments which determines the ability of the nanocrystals to change their structure. The analysis of bands resolution (Fig. 5) indicates that the latest incorporated ions are in less crystalline domains and suggests a progressive
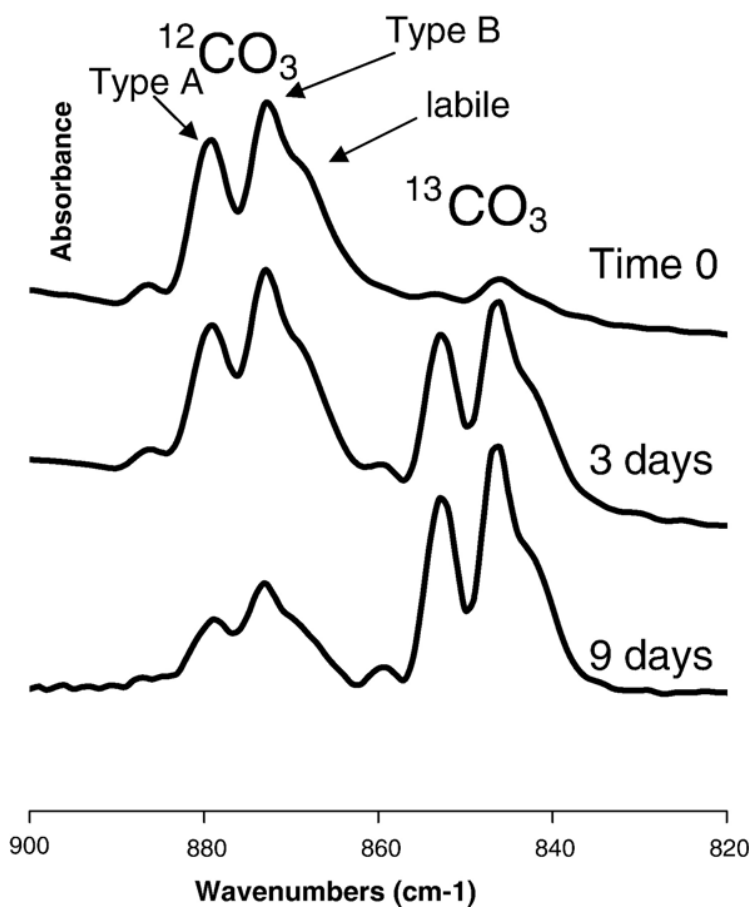

Fig. 4. FTIR spectra in the carbonate domain $\left(v_{2} \mathrm{CO}_{3}\right)$ illustrating the maturation process of nanocrystalline apatites (self-deconvoluted). The samples were precipitated in ${ }^{13} \mathrm{CO}_{3}$-containing solution [29], aged for 0,3 and $9 \mathrm{~d}$, filtered and transferred to a ${ }^{12} \mathrm{CO}_{3}$-containing solution for 3 weeks. The spectra show the evolution of the ${ }^{12} \mathrm{CO}_{3}$ and ${ }^{13} \mathrm{CO}_{3}$ bands in the $v_{2}$ domain. Three bands are observed corresponding to type A carbonate (carbonate replacing $\mathrm{OH}^{-}$in hydroxyapatite), type B carbonate (carbonate replacing phosphate) and labile carbonate in the hydrated layer [13]. At the moment of precipitation, a very few ${ }^{13} \mathrm{CO}_{3}^{2-}$ are taken up (sample 0) most of the carbonate was incorporated during the maturation process in the ${ }^{12} \mathrm{CO}_{3}^{2-}$ solution. As the precipitate is ageing in the ${ }^{13} \mathrm{CO}_{3}^{2-}$-containing solution the ${ }^{13} \mathrm{CO}_{3}^{2-}$ carbonate bands increase and the incorporated ${ }^{12} \mathrm{CO}_{3}$ after solution exchange decreases accordingly. The total carbonate content of all samples is similar. Once incorporated the carbonate ions are not removed by changing the solutions. The distribution between type A and type B is very similar during the maturation process in any solution. The maturation ability is limited and aged samples are practically inert.

development of apatite domains at the expense of the hydrated layer. This maturation process occurs in bone and the crystal maturity is related to the remodelling rate. Thus, the mineral crystals are generally more immature and contain more nonapatitic environments in the epiphysis of long bones (fast remodelling rate) than in the diaphysis (slow remodelling rate).

Another interesting property of apatite nanocrystals is related to the ion mobility in the hydrated layer which allows ion exchange reactions without altering the apatitic core.

\subsection{Ion exchange reactions}

The possibility to rapidly and reversibly exchange mineral ions in bone was first established and studied by Neuman et al. [21]. The ions of the hydrated layer constitute a pool of loosely bound mineral ions which can be easily replaced by other ions from the solution. Not all the possibilities of these exchange reactions are known yet. The first experiments concerned essentially bivalent cations and anions. Moreover, it has been found that some monovalent ions like $\mathrm{Na}^{+}$and $\mathrm{K}^{+}$could not be 


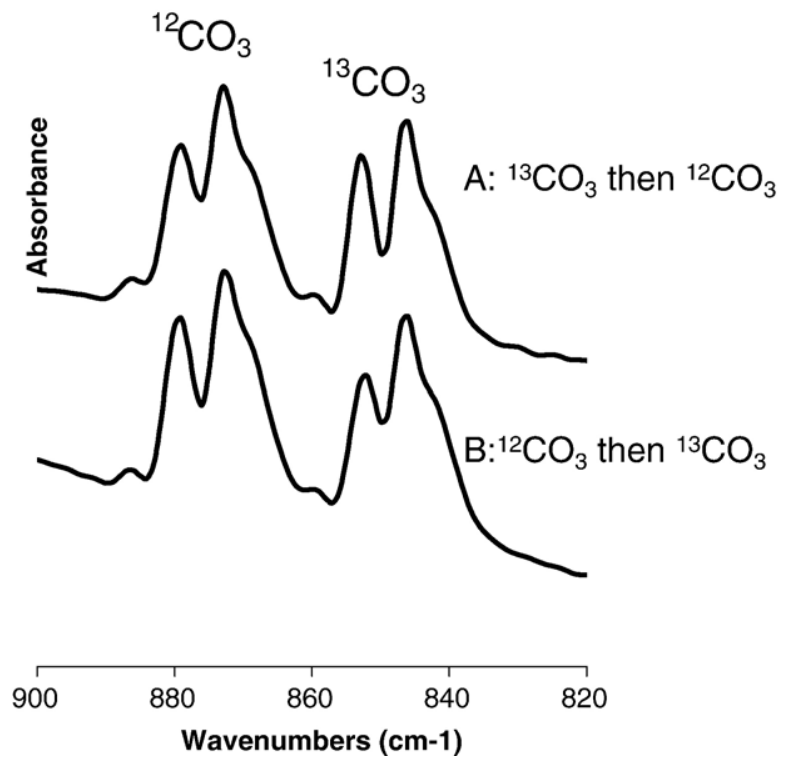

Fig. 5. Comparison of the FTIR spectra of nanocrystalline samples precipitated and aged in different solutions (self-deconvoluted). Sample A: precipitated in ${ }^{13} \mathrm{CO}_{3}$-containing solution kept for $3 \mathrm{~d}$ and then aged in ${ }^{12} \mathrm{CO}_{3}$-containing solution for 3 weeks. Sample B: precipitated in ${ }^{12} \mathrm{CO}_{3}$-containing solution kept for $3 \mathrm{~d}$ and then aged in ${ }^{13} \mathrm{CO}_{3}$-containing solution for 3 weeks. The first incorporated carbonate species exhibit a better resolution of the carbonate bands indicative of a location in domains with a better crystallinity. These data suggest a progressive development of the apatite domains

incorporated [31,32]. The exchange rates are very fast and an exchange equilibrium is reached within a few minutes. Analysis of the solid and the solution concentrations confirms that the exchange reactions result from the replacement of one ion of the solid by one ion from the solution without any other alteration of the solid composition, especially no change in apatite stoichiometry. The exchange reactions can be represented by a Langmuir-type isotherm. The affinity constant and the substitution limit depend on the nature of the ions. The exchange reactions do not however appear as a reversible equilibrium as in regular Langmuir-type adsorption. Dilution of the exchange solutions, for example, implies a decrease of the equilibrium concentration in solution but it does not involve a release of exchanged ions according to the isotherm representation. Once the ions have been incorporated they cannot be removed by dilution and the apatites can be washed without major ion loss. However, the exchanged ions can be almost totally removed by treating the nanocrystals in concentrated solutions of calcium or phosphate and only a very few foreign ions then remain in the solid. These data show that the exchange reactions involve a complex equilibrium of at least two ions competing for the same location and they can be represented as:

$\mathrm{Ca}_{\text {apat }}^{2+}+\mathrm{FC}_{\text {sol }}^{2+} \leftrightarrow \mathrm{Ca}_{\text {sol }}^{2+}+\mathrm{FC}_{\text {apat }}^{2+}$ for cations (FC: foreign cation)

$\mathrm{HPO}_{4}^{2-}$ apat $+\mathrm{FA}_{\text {sol }}^{2-} \leftrightarrow \mathrm{HPO}_{4}^{2-}$ sol $+\mathrm{FA}_{\text {apat }}^{2-}$

for anions (FA: foreign anion)

The corresponding equilibrium constants depend on the nature of the ions, on the composition of the apatite and on its maturation stage. It has been shown that ion exchanges are associated with a perturbation of the hydrated layer structure which also appears to be reversible [27]. The pool of exchangeable ions depends on the maturation state of the nanocrystals and on the extent of the hydrated layer. As this layer progressively decreases in proportion to the crystals maturation, the amount of exchangeable ions decreases accordingly [5]. The ability for foreign ions to substitute in the hydrated layer is greater than that observed with the regular apatite lattice. Thus ions like $\mathrm{Mg}^{2+}$, for which only a limited number can enter the hydroxyapatite lattice, are able to easily substitute for calcium ions from the hydrated layer through ion exchange reactions. Another interesting behaviour is observed during the maturation of apatite nanocrystals which have been submitted to ion exchange reactions. For $\mathrm{Mg}$-exchanged nanocrystals, the apatite domain is still growing during maturation but the magnesium ions always remain exchangeable (Fig. 6). The situation for $\mathrm{Sr}-$ exchanged nanocrystals is different since $\mathrm{Sr}^{2+}$ ions can easily replace calcium ions in the apatite structure. During the maturation, the growing apatite domains progressively incorporate $\mathrm{Sr}^{2+}$ ions and the amount of exchangeable $\mathrm{Sr}^{2+}$ ions constantly decreases with time (Fig. 6). These observations have some implications concerning foreign bone-seeking mineral ions which can either be toxic or, on the contrary, may play a beneficial role. These elements have the tendency to be trapped in tissue areas with a high remodelling rate like the epiphysis of long bones, corresponding to immature mineral rich in non-apatitic environments and also bones from young children in the growing stage which are much more sensitive than those of older people. Boneseeking elements can be trapped either by ion exchange between the ions of the hydrated layer and body fluids or by co-precipitation during bone formation or remodelling. Depending on their distribution between the hydrated layer and the apatite domains, these elements may remain available or not for further ion exchanges with body fluids. However, as maturation progresses, they can be trapped in the apatite lattice and reappear only during remodelling periods.

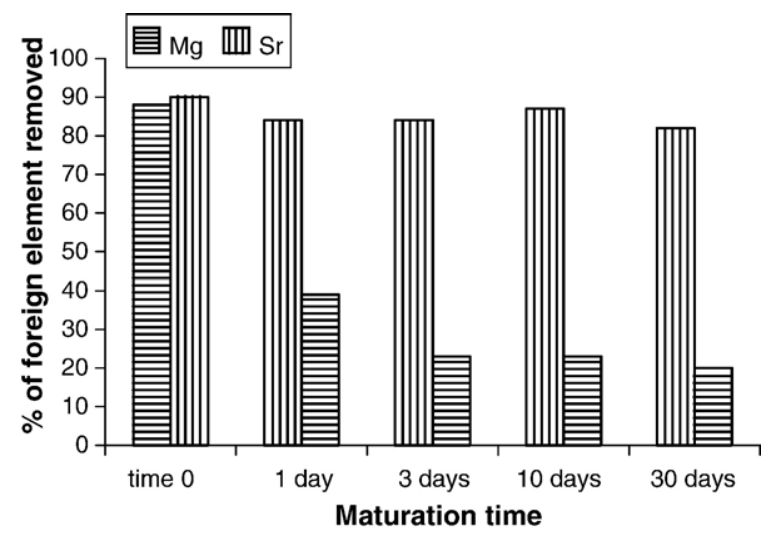

Fig. 6. Inverted exchange reaction on Mg-containing and Sr-containing nanocrystals after different maturation times. $\mathrm{The}_{\mathrm{Mg}^{2+}}$ ions remain always exchangeable but the proportion of exchangeable $\mathrm{Sr}^{2+}$ decreases. $\mathrm{Mg}$ is not trapped in large amount in the apatite domains and remains in the hydrated layer whereas the $\mathrm{Sr}^{2+}$ ions are progressively incorporated in the apatite domains during maturation and become progressively inaccessible to exchange reactions. 


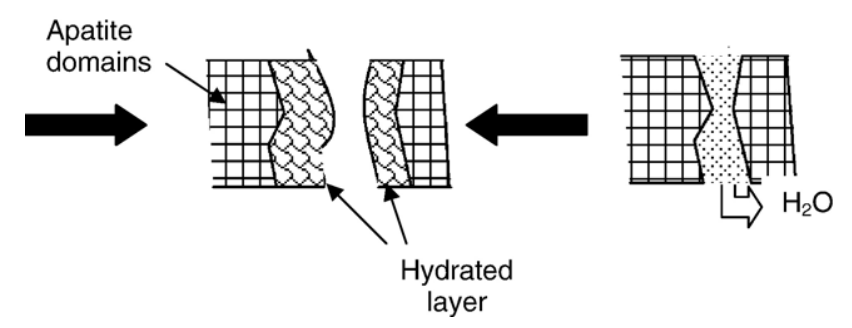

Fig. 7. Schematic representation of the crystal-crystal interactions through the hydrated surface layer. The crystal fusion may be associated with foreign ions and possibly molecules trapping.

In nanocrystals the composition of the hydrated surface layer contributes, for a non-negligible proportion, to the global composition. Although containing mainly divalent ions, the composition of the hydrated layer cannot be determined with accuracy. Exchange reactions are not complete and the amount of exchanged ions depends on their nature. In addition, as the hydrated layer cannot be isolated it is not possible to standardise spectroscopic methods for detailed studies. It can however be ascertained that the chemical compositions proposed for nonstoichiometric apatites have to take the existence of this layer into account. Thus the proposed formulae, although giving the global composition, do not really account for the composition of the true apatite domains.

\subsection{Adsorption of organic molecules}

Very few studies have been done on the adsorption of organic molecules on well characterised nanocrystalline apatites [33,34]. The results show Langmuir-type isotherms and indicate an increase of the affinity constant and a decrease of the coverage ratio as maturation time increases. The increase of the affinity constant can be correlated with the probable increase of interfacial energy of the nanocrystals during maturation in aqueous media. The comparison of the surface energy of several well crystallized hydrated and non-hydrated $\mathrm{Ca}-\mathrm{P}$ supports the suggestion that the hydrated surface layer decreases the interfacial energy with the solution and favours the nucleation and growth of the nanocrystals [26]. However, as the stable apatite domains grow with time, the interfacial energy should increase towards that of well crystallised apatite surfaces. According to the model proposed by Gibbs, the adsorption of molecules at an interface involves a decrease of the interfacial energy and it may be considered that if the energy of the nanocrystal-water interface increases, then molecule adsorption should be energetically favoured. In order to confirm this, it seems important to determine the thermodynamic properties of nanocrystalline apatite surfaces. However, it can be already stated that adsorption on nanocrystalline apatites cannot be considered as a purely physical process at the interface. Adsorption generally involves the displacements of ions of the hydrated surface layer (calcium or phosphate) and a possible change of its structure. This is, from a thermodynamic point of view, an irreversible process and, as for ion exchanges, the release of adsorbed molecules is generally obtained by an inverted displacement involving calcium and phosphate solutions (or other mineral ions which may replace them in the hydrated layer such as carbonate, magnesium or strontium for example). Of course calcium and phosphate ions are always present in an aqueous solution due to solubility equilibrium and they also have to be taken into account in the adsorption equilibrium. Adsorption and ion exchange therefore represent different aspects of the substitution ability of the mobile ions of the hydrated layer as schematised in Fig. 8. The decrease of the number of adsorption sites after increasing maturation time can thus be interpreted as a decrease of potentially exchangeable ions in the hydrated layer or a change in the equilibrium constants. Detailed studies will have to be performed for a better understanding of these reactions, especially from a thermodynamic point of view. The variable adsorption properties of nanocrystalline apatites depending on the maturation time probably affect complex regulating phenomena, in vivo, but they are as yet almost completely unknown. Among the potentially important consequences, are the role of organic-mineral interactions in the mechanical properties of bone tissue nanocomposite and the regulation of remodelling processes through protein adsorption and release, including adsorption effects on nucleation, growth and maturation of the nanocrystals. These properties have several consequences in materials science.

\section{Consequences of the structure and properties of apatite nanocrystals in material science}

The structure and properties of apatite nanocrystals open several possibilities in material science which can also play an important role in living organisms. One of the most interesting is the ability of crystals to join and interact. But nanocrystals can also interact strongly with different substrates and macromolecules via their surfaces.

\subsection{Crystal-crystal interactions}

The junction and adhesion of two apatite crystals to apparently form a single crystal has been described during the

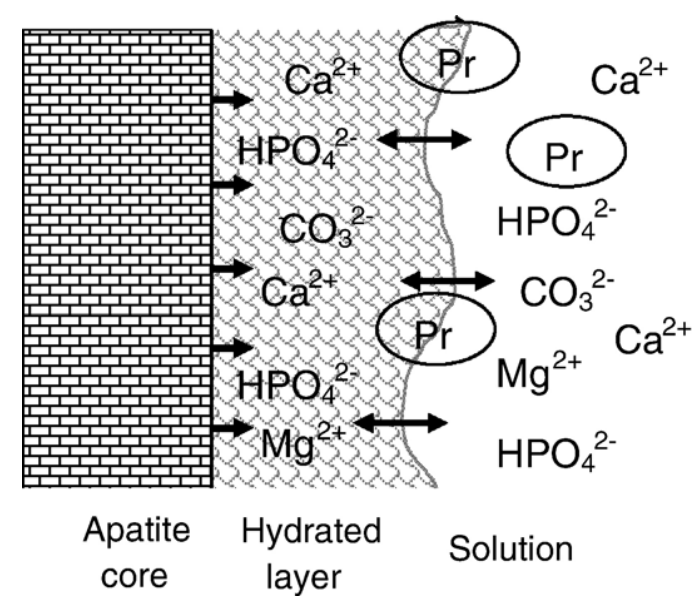

Fig. 8. Schematisation of surface reactions involving the hydrated surface layer. The structured hydrated layer constitute a pool of loosely bound ions which can be incorporated in the growing apatite domains and can be exchanged by foreign ions from the solution and charged groups of proteins (Pr). 
formation of various calcified tissues and is referred to as "crystal fusion" [35]. The structural and physical-chemical aspects of this phenomenon however are still poorly understood. According to the surface model of apatites proposed here, it can be described as a junction through the hydrated surface of apatite crystals. These domains could remain between adjacent old crystals. However, the increase of the crystal size upon ageing suggests that the hydrated layer junction could evolve towards apatite by a process not yet clarified, probably involving $\mathrm{Ca}^{2+}$ ion diffusion and $\mathrm{H}^{+}$elimination. Such processes could occur between nanocrystals for which the hydrated surface layer is well developed (Fig. 7). Such interactions have been promoted in gel-like suspensions of the nanocrystals [36]. The progressive drying increases crystal contact and reorientation; the progressive closeness enables the establishment of electrostatic interactions between the ions of the hydrated layers from the two crystals, possibly associated with the exclusion of water molecules in excess. Then the crystal junctions become very strong and the separation of joined crystals cannot be obtained by rehydration. Ceramics have been prepared using these capabilities of nanocrystals, however their compressive strength (at most $50 \mathrm{MPa}$ ) remains rather weak. The main difficulty to overcome is the shrinkage of the materials upon drying and the formation of cracks due to internal tensions between differently oriented domains of the ceramic.

The phenomenon of crystal fusion could also be at the origin of the incorporation of foreign ions or possibly inclusion clusters in the apatite crystals. This property could be the basis of crystal associations with very specific arrangements. Nevertheless, these capabilities do not seem to have been made use of yet.

\subsection{Crystal-substrate interactions}

The hydrated layer can interact with different substances and the related surface ion mobility could be involved in strong crystal adhesion onto different surfaces. One of the most interesting capabilities is the bonding to metals such as titanium to the coat prostheses with a bioactive layer. The surfaces of titanium and related alloys are covered by an oxide layer and, in aqueous media, this layer hydrolyses, forming a hydrated oxide-hydroxide layer. The interactions between nanocrystals and the titanium surface could involve the hydrated surfaces. Several reports have mentioned the possibility to associate apatite nanocrystals with titanium surfaces $[37,38]$. One of the main problems is to favour crystal-substrate interactions. In most instances such coatings are obtained from supersaturated solutions associated (or not) with an additional process to accelerate and favour the deposition (electrolysis, ion diffusion, $\mathrm{pH}$ variation, temperature increase, etc.). However, to avoid the use of supersaturated solutions in an industrial environment, other processes such as slow hydrolysis of precursors of apatite crystals like amorphous calcium phosphate have also been tested with some success. Very few studies have been made on the adhesion of such coatings and on the possible existence of preferential orientations of the crystals and practically no studies have investigated the bonding scheme between nanocrystals and different substrates, except for theoretical models based on epitaxial relationships between dry substrate surfaces and dry apatite surfaces. The direct bonding of existing nanocrystals on metallic substrates has not yet been successfully experimented. The main problem in this case is to avoid intercrystalline interactions which favour nanocrystal clustering instead of spreading over the surface to be coated. However the modification of the crystals and/or substrate surfaces could possibly solve these difficulties.

\subsection{Crystal-molecule interactions}

Several molecules can interact through ionic end groups with the surface ions of the hydrated layer; however, these capabilities have rarely been used in materials science. The incorporation of small molecules in apatite has been occasionally reported $[39,40]$. Similarly, dicarboxylic acids can be trapped in the OCP structure [41]. In all cases the hydrated layer could play a major role. Thus, it has been shown that the trapping of oxygen molecules in apatites is related to the decomposition of peroxide groups, essentially, from molecular $\mathrm{H}_{2} \mathrm{O}_{2}$ and $\mathrm{O}_{2}^{2-}$ ions associated with the apatite structure [40]. Although a relationship cannot be established between the incorporation of relatively small molecules into $\mathrm{Ca}-\mathrm{P}$ crystals and the formation of composites including macromolecules, similar types of interactions could be involved, especially mineral ion substitutions by charged groups in the hydrated layer. In biological mineralisation, these capabilities seem to have been exploited, although the fine details of protein and apatite nanocrystal interactions remain unknown. Interactions between proteins and apatite nanocrystals are generally thought to occur through anionic groups of the proteins. The involvement of several proteins has been established in the nucleation of the crystals and their growth control [42]. However, most of them occur at very low concentrations in the tissue. From a materials science viewpoint, the most important interactions, especially regarding mechanical and structural properties of bone tissues, involve mainly collagennanocrystals interactions. Several studies have shown that the first nuclei of mineral crystals first appear in the charged zone of the collagen molecules [43], and that the nanocrystal platelets are organised with their longitudinal axis along the fibre axis and the planes of the platelets parallel to each other $[35,44]$. The interactions occurring between the platelets and the collagen molecules at a molecular level have not yet been clarified. Bone tissue can however be described as a hybrid material consisting of an intimate association of organic macromolecules and mineral crystals. In materials science, these interactions could be exploited to form hybrid materials: a promising field which has yet to be investigated.

\section{Conclusions}

In summary, several properties of apatite nanocrystals can be related to the existence of a hydrated surface layer containing loosely bound mineral ions. This unstable structure constitutes an ion reservoir for the slow growth of the apatite domains. The loosely bound ions of the hydrated layer offer a wide range of reaction possibilities from ion exchange to the adsorption of organic molecules which have been largely exploited in living 
systems but are only beginning to be utilised in materials science to obtain nanostructured ceramics and adherent coatings on various substrates.

\section{References}

[1] M.J. Glimcher, in: F.L. Coe, M.J. Favus (Eds.), Disorders of Bone and Mineral Metabolism, Raven Press, New York, 1992, p. 265.

[2] S.V. Dorozhkin, M. Epple, Angew. Chem. 41 (2000) 3130.

[3] A. Bigi, G. Cojazzi, S. Panzavolta, A. Ripamonti, N. Roveri, M. Romanello, K. Noris suarez, L. Moro, J. Inorg. Biochem. 68 (1997) 45.

[4] I. Zizak, P. Roschger, O. Paris, B.M. Misof, A. Berzlanovich, S. Bernstorff, H. Amenitsch, K. Klaushofer, P. Fratzl, J. Struct. Biol. 141 (2003) 208.

[5] S. Cazalbou, C. Combes, D. Eichert, C. Rey, M.J. Glimcher, J. Bone Miner. Metab. 22 (2004) 310.

[6] L. Hench, J.W. Hench, D. Greenspan, J. Aust. Ceram. Soc. 40 (2004) 1.

[7] T. Kokubo, H.M. Kim, M. Kawashita, Biomaterials 24 (2003) 2161.

[8] P. Li, X. Ye, I. Kangasniemi, J.M. de Blieck6hogervorst, C.P. Klein, K. de Groot, J. Biomed. Mater. Res. 29 (1995) 325.

[9] C. Loty, J.M. Sautier, H. Boulekbache, T. Kokubo, H.M. Kim, N. Forest, J. Biomed. Mater. Res. 49 (2000) 423.

[10] L.M. Miller, V. Vairavamurthy, M.R. Chance, R. Mendelsohn, E.P. Paschalis, F. Betts, A.L. Boskey, Biochim. Biophys. Acta 1527 (2001) 11.

[11] S.J. Gadaleta, N.P. Camacho, R. Mendelsohn, A.L. Boskey, Calcif. Tissue Int. 58 (1996) 17.

[12] C. Rey, B. Collins, M. Shimizu, M.J. Glimcher, Calcif. Tissue Int. 46 (1990) 384.

[13] C. Rey, B. Collins, T. Goehl, R.I. Dickson, M.J. Glimcher, Calcif. Tissue Int. 45 (1989) 157.

[14] J.C. Elliott, Structure and Chemistry of the Apatites and Other calcium Orthophosphates, Elsevier, Amsterdam, 1994.

[15] G. Montel, G. Bonel, J.C. Heughebaert, J.C. Trombe, C. Rey, J. Cryst. Growth 53 (1981) 74.

[16] J.C. Heughebaert, G. Montel, Coll. Internat. CNRS, vol. 230, 1975, p. 283.

[17] R. Legros, N. Balmain, G. Bonel, Calcif. Tissue Int. 41 (1987) 137.

[18] W. Brown, L. Schroeder, J. Ferris, J. Phys. Chem. 83 (1979) 1385.

[19] M. Mathew, W.E. Brown, L.W. Schroeder, B. Dickens, J. Crystallogr. Spectrosc. Res. 18 (1988) 235.

[20] J.M. Burnell, E.J. Teubner, A.G. Miller, Calcif. Tissue Int. 31 (1980) 13.
[21] W.F. Neuman, T.Y. Toribara, B.J. Mulryan, J. Am. Chem. Soc. 78 (1956) 4263.

[22] K. Beshah, C. Rey, M.J. Glimcher, M. Shimizu, R.G. Griffin, J. Solid State Chem. 84 (1990) 71.

[23] Y. Wu, J. Ackerman, H.-M. Kim, C. Rey, A. Barroug, M.J. Glimcher, J. Bone Miner. Res. 17 (2002) 472.

[24] H. Sfihi, C. Rey, in: J. Fraissard, B. Lapina (Eds.), Magnetic Resonance in colloid and Interface Science, Kluwer Academic Publisher, 2002, p. 409.

[25] D. Eichert, M. Salome, M. Banu, J. Susini, C. Rey, Spectrochim. Acta, Part B: Atom. Spectrosc. 60 (2005) 850.

[26] D. Eichert, H. Sfihi, C. Combes, C. Rey, Key Eng. Mater. 254-256 (2004) 927.

[27] D. Eichert, C. Combes, C. Drouet, C. Rey, Key Eng. Mater. 284-286 (2005) 3 .

[28] C. Rey, A. Hina, S. Amrah-Bouali, X. Ranz, in: A. Ravaglioli (Ed.), Fourth Euro-Ceramics Symposium- Bioceramics, Gruppo Editoriale Faenza Editrice Spa, Faenza, 1995, p. 301.

[29] C. Rey, A. Hina, A. Tofighi, M.J. Glimcher, Cells Mater. 5 (1995) 345.

[30] J.D. Pasteris, B. Wopenka, J.J. Freeman, K. Rogers, E. Valsami-Jones, J.A.M. van der Houwen, M.J. Silva, Biomaterials 25 (2004) 229.

[31] S. Cazalbou, PhD thesis INPT, Toulouse (2000).

[32] D. Eichert, PhD thesis INPT, Toulouse (2001).

[33] S. Ouizat, A. Barroug, A. Legrouri, C. Rey, Mater. Res. Bull. 34 (2000) 2279.

[34] L. Benaziz, A. Barroug, A. Legrouri, C. Rey, A. Lebugle, J. Colloid Interface Sci. 238 (2001) 48.

[35] W.J. Landis, M.J. Song, A. Leith, L. McEwen, B.F. McEwen, J. Struct. Biol. 110 (1993) 39

[36] S. Sarda, A. Tofighi, M.C. Hobatho, D. Lee, C. Rey, Phosphorus Res. Bull. 10 (1999) 208.

[37] F. Barrere, C.A. van Blitterswijk, K. de Groot, P. Layrolle, Biomaterials 23 (2002) 2211

[38] X. Liu, X. Zhao, R.K. Fu, J.P. Ho, P.K. Chu, Biomaterials 26 (2005) 6143.

[39] S.E.P. Dowker, J.C. Elliott, J. Solid State Chem. 47 (1983) 164.

[40] C. Rey, J.C. Trombe, G. Montel, J. Inorg. Nucl. Chem. 40 (1978) 27.

[41] M. Markovic, B.O. Fowler, W.E. Brown, Chem. Mater. 5 (1993) 1401.

[42] A. Boskey, Connect. Tissue Res. 35 (1996) 357.

[43] W. Traub, T. Arad, S. Weiner, Matrix 12 (1992) 251.

[44] W. Traub, T. Arad, S. Weiner, Proc. Natl. Acad. Sci. U. S. A. 86 (1989) 9822. 